\title{
A Colônia Japonesa de Ivoti - primeiro relato de uma pesquisa interdisciplinar
}

\section{Prof. Dr. Johannes Doll, Faculdade de Educação, UFRGS}

Dra. Geraldine Alves dos Santos, Faculdade de Serviço Social, PUC/RS Prof. Tomoko Kimura Gaudioso, Instituto de Letras,
UFRGS

Há 45 anos atrás, em 1967, o primeiro habitante da futura Colônia Japonesa de Ivoti instalou-se no lote 25 que acabara de sortear e, desta forma, deu início ao maior projeto de colonização de um grupo de imigrantes japoneses no Estado do Rio Grande do Sul, Brasil. A Colônia desenvolveu-se durante este tempo, enfrentando e vencendo dificuldades e desafios. Transcorridas mais de quatro décadas, o número inicial de 26 famílias aumentou para mais ou menos 40 famílias. Estas famílias conseguiram, através de uma agricultura intensiva em propriedades pequenas, alcançar certa prosperidade.

A Colônia Japonesa de Ivoti é uma das mais recentes experiências de um grupo de imigrantes no Brasil. As migrações populacionais, sempre existentes na história humana e hoje intensificadas pelas condições facilitadas de transporte, constituem um campo interessante e fascinante de pesquisas ${ }^{1}$. Os estudos sobre grupos de imigrantes não são restritos a um único campo científico. A complexidade da situação dos imigrantes exige olhares multidisciplinares, pois envolve seres humanos nos seus múltiplos aspectos sociais, psicológicos e culturais.

$\mathrm{O}$ artigo sobre a Colônia Japonesa de Ivoti se divide em duas partes. Na primeira parte serão abordados os diferentes enfoques da pesquisa, bem como algumas fundamentações teóricas. Na segunda parte serão apresentados os primeiros resultados desta pesquisa. Respeitando as especificidades do campo, a pesquisa é concebida como 
interdisciplinar e acontecerá em três fases. Em uma primeira fase, pesquisadores ${ }^{2}$ de diferentes ciências exploram em conjunto o campo de pesquisa através de entrevistas, visitas e observações. Após a estruturação observacional do campo e a delimitação das questões relevantes, a pesquisa continua de forma separada, agora cada grupo aprofunda aspectos específicos de suas áreas. A terceira fase juntará de novo o grupo de pesquisa como todo, para tecer uma visão multidisciplinar sobre a situação da Colônia Japónesa de Ivoti. Os resultados obtidos por este processo serão colocados à disposição da comunidade de Ivoti possibilitando, desta forma, um olhar diferente a respeito da própria realidade. Espera-se que os resultados possam servir à Colônia de Ivoti no sentido de contribuir para um auto-conhecimento e para fundamentar decisões.

\section{Enfoques da pesquisa}

Das várias questões interessantes a serem abordadas, a pesquisa concentra-se nos aspectos jurídicos, lingüísticos, culturais, educacionais e gerontológicos. As questões jurídicas são normalmente os primeiros desafios para um imigrante. Questões importantes neste contexto referem-se à condição jurídica do estrangeiro envolvendo o estatuto do estrangeiro, permissão de entrada e de permanência, vistos, asilo, deportação e exigências para visto de trabalho ${ }^{3}$. Outro aspecto importante refere-se à aquisição da nacionalidade do novo país, à possibilidade de dupla nacionalidade bem como à regulamentação da nacionalidade dos descendentes ${ }^{4}$. Para os imigrantes já instalados no novo país, questões do Direito Internacional Privado tornam-se importantes, especialmente no que concerne ao reconhecimento de sentenças e de direitos adquiridos. Neste contexto, uma área especialmente importante é o Direito de Família 5

\footnotetext{
${ }^{1} \mathrm{Na}$ verdade, o contato com o outro, o diferente na forma de outras pessoas e outras sociedades pode ser entendido como a base da própria ciência. A confrontação com normas e regras diferentes dos nossos questiona as nossas normas e valores "normais", exige reflexão e fundamentação. Störig demonstra como a filosofia e a ciência grega desenvolveram-se a partir dos contatos com outros povos e outras formas de pensar durante suas viagens marítimas (veja: Störig, Hans Joachim. Kleine Weltgeschichte der Philosophie, Bd. 1. Frankfurt a. M.: Fischer, 1981, p. 120).

2 Além dos três autores, a pesquisa conta com a colaboração da Profa. Dra. Claudia Lima Marques (Faculdade de Direito, UFRGS), da psicóloga Caroline Stumpf Buaes, dos acadêmicos em direito Antonia Klee, Ana Gerdau de Borja, Bibiana Graeff Chagas Pinto, Lucas Annes, Maitê Schmitz, Simone Regina Backes e da acadêmica em filosofia Aline Midori de Moraes Tanaka.

${ }^{3}$ Veja, a respeito, Cavarzere, Thelma Thais. Direito Internacional da Pessoa Humana. A circulação internacional de pessoas. $2^{a}$ ed., revista e atualizada. Rio de Janeiro, São Paulo: Renovar, 2001.

${ }^{4} \mathrm{~A}$ grande maioria dos países de imigração adotaram o Jus Soli. A respeito dos diferentes conceitos de nacionalidade e das origens a interpretações do Jus Sanguinis e do Jus Soli, veja Del'Olmo, Florisbal de Souza. O Mercosul e a nacionalidade: estudo à luz do direito internacional. Rio de Janeiro: Forense, 2001. Veja, também, Dal Ri Júnior, Arno; Oliveira, Odete Maria de (orgs.). Cidadania e nacionalidade: efeitos e perspectivas nacionais, regionais, globais. ljuí: Ed. Unijui, 2002.

${ }^{5}$ Sobre o desenvolvimento do Direito de Familia no Brasil, veja Fradera, Vera Jacob de. Evolución y Estado Actual del Derecho de Familia en Brasil. In: Carlucci, Aida Kemelmajer de (org.). El Derecho de Familia y los Nuevos Paradigmas. Tomo III. Buenos Aires, Santa Fe: Rubinzal, Culzoni, 2000, p. 221-235.
} 
Um outro desafio importante para o imigrante é a comunicação no novo país, especialmente quando as línguas são tão diferentes como o português e o japonês. Para poder comunicar-se com outras pessoas do novo país, é necessária a aquisição de uma nova língua. Existe uma longa tradição de estudos sobre a interação entre línguas diferentes e os processos de aquisição da nova língua ${ }^{6}$. Estudos apontam para um processo de aquisição da nova língua do país, dependendo principalmente $\dot{d} a$ necessidade de comunicação com outros membros fora da sua comunidade lingüística. Os imigrantes nesta fase tornam-se, portanto, bilíngües, mesmo que o domínio das duas línguas seja em níveis diferentes. A manutenção da língua de origem depende de uma série de fatores, mas existe o perigo de perder esta língua dentro de duas a quatro gerações ${ }^{7}$. Estudos mais atuais, porém, destacam a multiplicidade de fatores que podem contribuir para a manutenção de um bilinguismo entre os grupos de imigrantes ${ }^{8}$.

Aspectos culturais têm sido tradicionalmente abordados para discutir a questão dos imigrantes ${ }^{9}$. Neste contexto, o conceito de cultura é compreendido de forma mais abrangente, não se limitando a aspectos folclóricos ou musicais. Cultura no sentido de uma cultura do dia-a-dia diz respeito a um "conjunto de traços característicos do modo de vida de uma sociedade, de uma comunidade ou de um grupo, aí compreendidos os aspectos que podem se considerar como os mais cotidianos, os mais triviais ou os mais "inconfessáveis" "10. A aculturação de um grupo de imigrantes pode ser considerada, nesta compreensão de cultura, como um processo de interação, negociação e ajustamento entre comportamentos de membros do país de recepção e os imigrantes. Este "jogo" não acontece somente no campo do comportamento, mas também nas representações sociais e simbólicas. Outro aspecto importante é o fato de que nas discussões atuais, o próprio país de recepção não é mais entendido como um bloco culturalmente homogêneo, mas composto pelas mais variadas culturas, as quais podem entrar em contato com a cultura dos imigrantes, geralmente também não homogênea.

\footnotetext{
${ }^{6}$ Uma perspectiva abrangente sobre a questão de línguas em contato permitem as seguintes obras: Edwards, John. Multilingualism. London, New York: Routledge, 1994; Romaine, Suzanne. Bilingualism. Second Edition. Oxford: Blackwell, 1995. As mudanças no comportamento lingüistico em situação de minoria são estudados de forma profunda e competente por Kaufmann, Göz. Varietätendynamik in Sprachkontaktsituationen. Attitüden und Sprachverhalten russlanddeutscher Mennoniten in Mexiko und den USA. Frankfurt a. M.: Lang, 1997. Veja, também, Doll, Johannes. Geschichtstexte verstehen in einer anderen Sprache. Frankfurt a. M.: Lang, 2002, capitulo 2.

7 Veja, por exemplo, Weimer, Wendy P. Factors affecting native language maintenance. In: Padilla, Raymond E. (ed.). Ethnoperspectives in Bilingual Education Research, Vol II: Theory in Bilingual Education. Ypsilanti: Eastern Michigan University, 35-46.

${ }^{8}$ Baker agrupa os fatores que influenciam a manutenção ou a perda de uma lingua em fatores políticos, sociais e demográficos, fatores culturais e fatores sociolingüisticos, seguindo um trabalho de Conklin \& Lourie (Baker, Colin. Foundations of Bilingual Education and Bilingualism. Clevedon, Philadelphia, Adelaide: Multilingual Matters, 1993).

${ }^{9}$ Veja, por exemplo, Willems, Emilio. A Aculturação dos Alemães no Brasil. Estudo antropológico dos imigrantes alemães e seus descendentes no Brasil. São Paulo: Companhia Editora Nacional, 1946.

${ }^{10}$ Forquin, Jean-Claude. Escola e Cultura; As bases sociais e epistemológicas do conhecimento escolar. Porto Alegre: Artes Médicas, 1993.
} 
Outros conceitos usados na discussão cultural são os da identidade e da etnia, que se referem ao sentimento subjetivo de pertencer a um determinado grupo. Nos Estudos Culturais, entende-se a questão da identidade como um resultado produzido em discursos, onde representações sociais e individuais, regulamentações de diferentes formas, bem como aspectos de produção e consumo interagiram. Nesta perspectiva, a identidade é ao mesmo tempo produto e produtor dos fatores mencionados constituindo um círculo de interações ${ }^{11}$.

Em relação à educação, os imigrantes anteriores - no Rio Grande do Sul principalmente de origem italiana e alemã - deixaram fortes marcas no sistema educacional, até porque naquela época (século 19 , início século 20) não existia ainda um sistema consolidado de escolas no Brasil ${ }^{12}$. A necessidade de discutir a questão educacional em relação às imigrações deve-se também ao fato de que as escolas constituem, em muitos casos, um elo importante entre o grupo de imigrantes e o país de recepção, tanto para a aquisição da nova língua, quanto à introdução a conhecimentos importantes daquele país e até a respeito de valores transmitidos no contexto escolar.

O último aspecto abordado da pesquisa, questões gerontológicas, parece ainda pouco comum em estudos sobre imigrantes. Mesmo assim trata-se de uma questão altamente importante, que cada vez mais chama a atenção dos pesquisadores ${ }^{13}$. Além

11 O modelo interessante (Paulo de Gay et al., 1997) de um circuito de cultura, que produz a identidade através da interação com representação, regulação, produção e consumo, é apresentado por: Woodward, Kathryn. Identidade e diferença: uma introdução teórica e conceitual. In: Silva, Tomaz Tadeu (org.). Identidade e diferença. A perspectiva dos Estudos Culturais. Petrópolis: Vozes, 2000, 7-72. No mesmo livro, um dos pesquisadores mais importantes dos Estudos Culturais, Stuart Hall, discute a quem serve o uso da identidade (Hall, Stuart. Quem precisa da identidade? In: Silva, Tomaz Tadeu (org.). Identidade e diferença. A perspectiva dos Estudos Culturais. Petrópolis: Vozes, 2000, 103-133.

12 Sobre esta questão, encontram-se principalmente estudos sobre as escolas teuto-brasileiras, por exemplo: Paiva, César. Die deutschsprachigen Schulen in Rio Grande do Sul und die Nationalisierungspolitik. Dissertation. Hamburg, 1984; Kreutz, Lúcio. O professor paroquial. Magistério e Imigração Alemã. Porto Alegre: Ed. da UFRGS, 1991. A respeito das escolas italianas, veja, por exemplo, os interessantes relatórios dos Cônsuls italianos no Rio Grande do Sul de 1876 a 1913. Manuscrito anotado e traduzido por Luís Alberto de Boni, Bento Gonçalves, 1994.

${ }^{13} \mathrm{Em}$ outros países já existe um número grande de pesquisas a respeito de imigrantes envelhecendo, especialmente nos Estados Unidos (Jackson, James S.; Antonucci, Toni C.; Gibson, Rose C. Cultural, Racial, and Ethnic Minority Influences on Aging. In: Birren, James E.; Schaie, K. Warner (eds.). Handbook of the Psychology of Aging. 3rd Ed. San Diego, London: Academic Press, 1990, 103132), mas também na Europa (Geiger, Ingrid; Brandenburg, Hermann. Seniorinnen und Senioren ausländischer Herkunft. In: Wahl, Hans-Werner; Tesch-Römer, Clemens (Hrsg.). Angewandte Gerontologie in Schlüsselbegriffen. Stuttgart, Berlin, Köln: Kohlhammer, 2000, 281-289. Também no Brasil estão surgindo alguns trabalhos nesta área, com grupos mais antigos de imigrantes, por exemplo, SANTOS, Geraldine Alves dos. Envelhecimento bem-sucedido, fatores socioculturais e personalidade em grupos de origem étnico-cultural alemã, italiana e mista. Tese de doutorado. PUCRS, Porto Alegre, 2000; França, Maria Cristina Caminha de Castilhos. A cidade narrada na memória dos velhos habitantes de Teutônia (RS): estudo etnográfico da memória compartilhada sobre as experiências transmitidas na relação entre avôs e netos. Dissertação de Mestrado. UFRGS, Porto Alegre, 2002. 
de aspectos como as relações familiares e o suporte de pessoas mais velhas, interessa também a imagem dos idosos e as suas representações sociais nas diferentes culturas, pois interferem no próprio comportamento em relação às pessoas mais idosas. Outra questão importante neste contexto, vinculado aos aspectos culturais, é o papel das pessoas idosas na manutenção da cultura dos imigrantes e na estruturação da própria família. Finalmente, interessa também a autopercepção das pessoas idosas, pois envelhecer em um outro país e dentro de outro contexto cultural significa um desafio adicional. A finalidade de estudos, neste campo, é a contribuição para um envelhecimento bem sucedido dos imigrantes na nova sociedade $^{14}$.

\section{Primeiros resultados da pesquisa}

A idéia de uma colônia própria surgiu no início dos anos 60 num grupo de imigrantes japoneses que tinha saído do Japão depois da segunda guerra ${ }^{15} \mathrm{e}$ tinha chegado no Rio Grande do Sul, diferentemente das primeiras gerações de imigrantes japoneses no Brasil, que foram para São Paulo na primeira parte do século XX. O grupo no Rio Grande do Sul ${ }^{16}$ dedicou-se, inicialmente, a plantar hortaliças, tomates e verduras. Mas o mercado ficou saturado e surgiram problemas financeiros. O dinheiro trazido do Japão acabou. Alternativas como plantar flores, arroz, frutas ou criação de gado foram discutidas, mas o problema básico foi a falta de terra própria para realizar estes projetos. Eles começaram a procurar terras adequadas para seus projetos, mas somente quatro anos depois encontraram um terreno perto da cidade de Ivoti. A aquisição das terras foi possível graças à ajuda do governo japonês que, através da Jica (Agência Internacional de Cooperação do Japão), financiou as terras de 120 hectares, dividiu em 26 lotes e sorteou entre as famílias japonesas interessadas. Isso significava terrenos em torno de 5 hectares aráveis por família. Uma grande parte das famílias que se registraram no sorteio eram do Rio Grande do Sul, mas também havia famílias japonesas de outros lugares. Na sua grande maioria eram famílias jovens, a maior parte dos adultos que formaram a Colônia tinham entre vinte e trinta anos de idade. Apesar das vantagens destas terras como solo adequado para árvores frutíferas, proximidade à capital Porto Alegre $(50 \mathrm{~km})$, infraestrutura como escolas e hospitais, o grande problema era a falta de água. Através de outros financiamentos, entre os quais do $\mathrm{BRDE}$, foi possível construir uma represa e adquirir bombas que levantassem a água por um desnível de 60 metros. Hoje existem duas redes independentes de água, uma para água potável, outra para a irrigação das plantas. Uma das condições impostas à Colônia era o cultivo de uvas. Durante muito tempo, a plantação de uvas de mesa constituiu a maior produção da Colônia. Nos últimos anos, esta produção diminuiu por várias razões. A produção de uva de mesa é um processo muito trabalhoso que envolve o uso intensivo de

${ }^{14}$ Sobre a influência da cultura à satisfação de vida, veja, Doll, Johannes. Satisfação de vida de homens e mulheres idosos no Brasil e na Alemanha. Cadernos Pagu, $n^{\circ} 13,1999,109-159$.

${ }^{15}$ Das 15 pessoas entrevistadas, só os antepassados de um tinham chegado no Brasil há mais tempo (1935), 12 dos 15 entrevistados chegaram entre 1957 e 1961.

${ }^{16}$ As informações sobre a história da Colônia Japonesa de Ivoti, bem como os dados apresentados são os resultados de 15 entrevistas com moradores da Colônia ou pessoas vinculadas à comunidade. 
agrotóxicos. Pelo envelhecimento da população da Colônia, por problemas de saúde que apareceram e também pelo desenvolvimento técnico, por exemplo no uso de estufas, a produção diversificou-se. A Colônia conta hoje com 40 famílias e o espaço inicial de 120 hectares aumentou. Os desafios para a manutenção da Colônia foram enfrentados de forma conjunta. Foi fundada uma cooperativa para a distribuição dos produtos, que já no início foram levados até São Paulo. Nas entrevistas foram destacados o esforço conjunto e as decisões democráticas referentes ao desenvolvimento da Colônia. Após 18 anos, os membros da Colônia conseguiram saldar suas dívidas referentes à aquisição das terras e à construção da infraestrutura. Foi mencionado também o apoio recebido pelos habitantes de Ivoti, pequena cidade do interior, a cinco quilômetros da Colônia, cuja população é predominantemente de descendência alemã. As plantações, as casas e os carros permitem a conclusão de que a Colônia de Ivoti conseguiu se desenvolver bem e que seus membros alcançaram certa prosperidade.

O primeiro levantamento de dados da pesquisa consistiu, além das observações e visitas, em entrevistas com moradores masculinos da Colônia. Até este momento foram realizadas vinte entrevistas, das quais quinze já foram tabeladas. Os resultados apresentados em seguida baseiam-se nos dados destas entrevistas. Os informantes pertencem a três gerações diferentes, isseis, nisseis e sanseis. A tabela 1 dá uma perspectiva geral dos entrevistados e das faixas etárias.

Tabela 1. Distribuição das pessoas entrevistadas, segundo geração de imigração e idade

\begin{tabular}{|c|c|c|c|c|c|c|}
\hline & \multicolumn{2}{|c|}{$1^{a}$ geração (isseis) } & \multicolumn{2}{|c|}{$2^{\text {a }}$ geração (nisseis) } & \multicolumn{2}{|c|}{$3^{\mathrm{a}}$ geração (sanseis) } \\
\hline Número de pessoas & \multicolumn{2}{|c|}{7} & \multicolumn{2}{|c|}{6} & \multicolumn{2}{|c|}{2} \\
\hline Faixa etária & \multicolumn{2}{|c|}{$\begin{array}{l}50-84 \text { anos; } \\
\text { média } 63 \text { anos }\end{array}$} & \multicolumn{2}{|c|}{$\begin{array}{c}31-44 \text { anos; } \\
\text { média } 38,3 \text { anos }\end{array}$} & \multicolumn{2}{|c|}{$\begin{array}{c}21-30 \text { anos; } \\
\text { média } 25,5 \text { anos }\end{array}$} \\
\hline \multirow[t]{2}{*}{ Nacionalidade } & japonesa & brasileira & Japonesa & brasileira & japonesa & brasileira \\
\hline & 6 & 1 & 0 & 6 & 0 & 2 \\
\hline
\end{tabular}

Aspectos jurídicos

A maioria das pessoas entrevistadas, da primeira geração, chegaram ao Brä̌słatravés do sistema "kousei kazoku", uma forma de imigração por família, que facilitava a entrada no Brasil, quando se tratava de uma família inteira. Às vezes, pessoas solteiras declararam-se membros de uma família que pretendia ir para o Brasil para poder aproveitar esta vantagem, o que não parece ter sido o caso das pessoas entrevistadas, pois os dois mais velhos tinham casado no Japão, portanto entraram no Brasil com suas respectivas famílias. Os outros três que chegaram pelo sistema "kousei kazoku" ainda eram menores e entraram juntos com seus pais.

Uma outra questão jurídica interessante é a nacionalidade. Neste ponto, nota-se uma clara vinculação à geração. Enquanto quase todos isseis - uma única exceção mantiveram sua nacionalidade japonesa, todos os nisseis e sanseis possuem exclusivamente a nacionalidade brasileira. Não foram informados outros casos de dupla nacionalidade. Morando no Brasil, os descendentes japoneses possuem a possibilidade de registrar seus 
casamentos, divórcios, nascimentos e óbitos no consulado japonês. Mas nem todos usam este serviço. Em relação aos casamentos, esta prática está se perdendo. Enquanto nos primeiros anos existe o hábito de registrar os casamentos (1968 - 1975), a partir dos anos 80 começa a mudança. Ainda há um registro em 1981, mas os quatro casamentos posteriores não são mais registrados. Em relação ao registro dos filhos observa-se diferentes práticas. Enquanto três registraram todos os seus filhos, dois registraram somente um dos filhos e três não registraram nenhum. Os sete restantes ou já tiveram os seus filhos no Japão ou (ainda) não têm filhos. Os óbitos são geralmente registrados, somente uma pessoa mencionou o não cadastramento de um familiar falecido.

Em relação à propriedade, ninguém possui bens no Japão, mas praticamente todos possuem terra no Brasil, como era de se esperar de uma colônia de agricultores. Ninguém mencionou alguma herança do Japão, que poderia ser outra questão jurídica interessante.

\section{Aspectos lingüísticos}

Como era de se esperar, as competências lingüísticas em português e japonês das pessoas entrevistadas são muito diferentes, dependendo da geração a que pertencem. Nota-se um claro aumento nas competências em português, enquanto fica evidente a perda do domínio em japonês nas gerações mais novas. Entre os isseis, todos falam japonês, quase todos sabem ler e escrever, somente uma pessoa não sabe escrever japonês. Já na próxima geração, estas competências se perdem, somente um entrevistado ainda sabe ler e escrever, os outros sabem somente um pouco da leitura e escrita japonesa. Na terceira geração temos dois casos, um que não fala mais japonês, enquanto um outro, através de aulas particulares, não só sabe falar japonês, mas também sabe ler e escrever. Em relação ao português, somente na primeira geração encontram-se pessoas com dificuldades na leitura e escrita, mesmo assim, a maioria sabe ler e escrever. A partir da segunda geração, a leitura e a escrita do português são normais, até pela formação escolar.

No segundo bloco são abordadas questões referentes ao uso de cada uma das línguas, à preferência e à competência, atribuída pela própria pessoa. Também se nota um movimento forte do japonês para o português, onde o menor uso leva a uma diminuição da competência e, em seguida, para uma preferência pela língua portuguesa. Na primeira geração, a maioria ainda usa mais o japonês, no entanto quase a metade admite falar mais o português. A partir da segunda geração identificamos que os entrevistados falam japonês somente com os membros mais velhos da Colônia, enquanto o português constitui a língua normal. Isso se reflete na competência, pois dos cinco dos sete isseis entrevistados apresentam maior competência na língua japonesa, já os nisseis e sanseis dominam mais o português. A preferência de uma língua não depende totalmente da competência, apesar de estar fortemente vinculada a esta. Assim encontram-se, entre a segunda e terceira geração, ainda pessoas que indicam não ter preferência no uso da língua, neste ponto razões tradicionais e emocionais impedem (ainda) um abandono da língua de origem. 


\begin{tabular}{|c|c|c|c|c|c|c|c|}
\hline & \multicolumn{2}{|l|}{ japonês } & \multicolumn{2}{|l|}{ português } & \multirow[t]{2}{*}{ maior uso } & \multirow[t]{2}{*}{ preferência } & \multirow[t]{2}{*}{ competência } \\
\hline & saber ler & sabe escrever & sabe ler & sabe escrever & & & \\
\hline $\begin{array}{l}\text { isseis } \\
(\mathrm{n}=7)\end{array}$ & $\begin{array}{l}5-\operatorname{sim} \\
2-\text { pouco }\end{array}$ & $\begin{array}{l}5-\operatorname{sim} \\
1-\text { pouco } \\
1-\text { não }\end{array}$ & $\begin{array}{l}5-\operatorname{sim} \\
2-\text { pouco }\end{array}$ & $\begin{array}{l}4-\operatorname{sim} \\
2-\text { pouco } \\
1 \text { - não }\end{array}$ & $\begin{array}{l}4 \text { japonês } \\
3 \text { portug. }\end{array}$ & $\begin{array}{l}5 \text { japonês } \\
2 \text { portug. }\end{array}$ & $\begin{array}{l}5 \text { japonês } \\
2 \text { portug. }\end{array}$ \\
\hline $\begin{array}{l}\text { nisseis } \\
(n=6)\end{array}$ & $\begin{array}{l}1-\operatorname{sim} \\
5-\text { pouco }\end{array}$ & $6-$ pouco & $6-\sin$ & $6-\operatorname{sim}$ & 6 portug. & $\begin{array}{l}4 \text { portug. } \\
2 \text { não têm }\end{array}$ & 6 portug. \\
\hline $\begin{array}{l}\text { senseis } \\
(\mathrm{n}=2)\end{array}$ & $\begin{array}{l}1-\operatorname{sim} \\
1-\text { não }\end{array}$ & $\begin{array}{l}1 \text { - sim } \\
1-\text { não }\end{array}$ & $2-\operatorname{sim}$ & $2-\operatorname{sim}$ & 2 portug. & $\begin{array}{l}1 \text { portug. } \\
1 \text { não tem }\end{array}$ & 2 portug. \\
\hline
\end{tabular}

Tabela 2. Distribuição por competências lingüísticas, uso e preferência

Além dos aspectos lingüísticos mencionados, a observação das relações entre as pessoas e as conversas com os pesquisadores demonstra claramente a existência de um bilinguismo japonês-português em grande parte dos membros da Colônia, mas ao mesmo tempo uma tendência forte para o uso da língua portuguesa. Enquanto os membros mais idosos da Colônia preferiram dar as entrevistas em japonês com a ajuda de intérprete, a partir da segunda geração não há nenhuma restrição no uso do português. Também entre os próprios nisseis, o português constitui hoje a língua de comunicação. A presença da língua japonesa ainda é forte, pois no Festival de Folclore - Enguekai da Colônia, a apresentação e comunicação acontece inteiramente em japonês, mas já os membros mais novos demonstram certas dificuldades em compreender tudo o que é falado.

\section{Aspectos culturais}

A expectativa de constatar, a partir das entrevistas, diferenças culturais claras entre a Colônia de Ivoti e o ambiente cultural do Rio Grande do Sul foi, de certa maneira, frustrada. A pergunta sobre percepções divergentes entre a Colônia e Porto Alegre, por exemplo, apontou muito mais para diferenças entre o interior e a cidade grande do que para diferenças culturais étnicas. Além de aspectos mais visíveis ou mais fáceis de serem constatados como o folclore, a comida e a autopercepção como "japonês" ou "brasileiro" ficou complicado um maior aprofundamento, pois as diferentes culturas, como a cultura camponesa, a cultura do interior, a cultura étnica, etc., se sobrepõem às identidades das pessoas e tornam complicada uma classificação simplória. A própria questão sobre cultura japonesa ficou difícil de ser respondida pelos membros da Colônia: cultura japonesa no Japão ou cultura japonesa na Colônia Japonesa de Ivoti? Estas questões exigirão ainda estudos mais aprofundados. Neste primeiro momento só é possível constatar, que a questão da comida se mostrou bastante estável, um vez que a grande maioria dos entrevistados até gosta da comida brasileira, mas mantêm os costumes alimentícios do seu país de origem, dentro das possibilidades da Colônia. Em relação à percepção da própria identidade, notam-se claras diferenças entre as gerações. Enquanto dos isseis, só um sente-se mais brasileiro, os outros se sentem mais japoneses (2) 


\section{Johannes Doll, Geraldine Alves dos Santos, Tomoku Kimura Gaudioso}

ou japoneses e brasileiros ao mesmo tempo (3) (um não respondeu), os nisseis e sonseis se sentem mais brasileiros. Um dos nisseis disse sentir-se japonês e brasileiro, mas no Japão ele sentir-se-ia brasileiro. Foi interessante o comentário de um dos nisseis entrevistados sobre a pergunta se ele sentir-se-ia mais brasileiro ou mais japonês: "Brasileiro. Só minha lataria é japonês, não que eu não gosto."

\section{Aspectos educacionais}

Desde o início, a existência de boas escolas foi uma preocupação para os membros da Colônia Japonesa de Ivoti. À pergunta de um governador sobre o que a Colônia precisava, a comunidade solicitou uma escola própria. Foi lá onde a segunda geração aprendeu o português, pois em casa falava-se, naquela época, ainda exclusivamente japonês. Pelos comentários, esta aprendizagem do português aconteceu sem maiores problemas, somente com um certo sotaque alemão, pois a professora era, como a maioria dos habitantes de Ivoti, de origem alemã.

A preocupação com a formação educacional reflete-se em um nível bastante elevado de instrução formal. Já a primeira geração trouxe do Japão uma boa formação escolar, dois terminaram o ensino básico, um o ensino fundamental, três concluíram o ensino médio e um possui formação universitária. Este nível ainda aumentou na segunda geração, onde dois concluíram o ensino médio e a formação técnica, enquanto os outros quatro possuem formação universitária. Da geração mais nova, um já concluiu a faculdade, enquanto o outro ainda está cursando. Trata-se de uma excelente formação para uma colônia agrícola.

\section{Aspectos gerontológicos}

A Colônia Japonesa de Ivoti formou-se no final dos anos 60. Isso significa que as pessoas, que na época construíram esta Colônia, têm hoje 60 anos ou mais. Interessante também é a análise da própria definição de quem é considerado velho ou não. Segundo os padrões internacionais, pessoas com mais que 65 anos nos países industrializados e mais que 60 anos nos países em desenvolvimento são considerados pessoas idosas. Na Colônia de Ivoti, a assembléia dos moradores, porém, preferiu uma outra classificação, considerando pessoas idosas somente a partir de 70 anos. Os registros deste grupo na Colônia demonstram o envelhecimento dos seus moradores. Enquanto em 1996 existiam 17 pessoas com 70 ou mais anos na Colônia, este número aumentou em 1999 para 20 e em 2001 para 23 pessoas.

Uma das maiores preocupações dos membros mais velhos da Colônia é a questão da continuidade do próprio projeto da Colônia. As ameaças vêm de dois lados. Os filhos dos fundadores possuem hoje uma excelente formação escolar e o trabalho no campo parece, para muitos, pouco atrativo. Com sua formação e seus estudos realizados em Porto Alegre ou em outras cidades maiores, eles encontram facilmente outros empregos 


\section{A Colônia Japonesa de Ivoti}

que parecem para eles mais atraentes. Além desta tendência da fuga do campo existe para os descendentes japoneses ainda uma outra possibilidade, o trabalho temporário no Japão, o "degasegui". Especialmente a perspectiva de ganhar bem mais do que no trabalho duro do campo atrai muitos descendentes. Isso significa uma certa desestruturação das famílias, quando o filho mais velho, tradicionalmente responsável pelo sustento dos pais velhos, não está mais presente. As primeiras impressões durante as entrevistas apontam para o fato de que este sistema de suporte familiar aos membros mais velhos ainda funciona. Se é necessário, o filho ainda volta para ajudar o pai. Todavia, nota-se um certo descontentamento neste segunda geração que pode, a longo prazo, colocar o sistema de apoio familiar em questão. Para afirmar estas tendências, porém, serão necessários estudos complementares.

\section{Conclusões}

A existência da Colônia de Ivoti significa a realização do sonho de um grupo de imigrantes japoneses, que chegaram na década de 50 e início de 60 no Brasil. Eles conseguiram sua própria terra, trabalho e uma certa prosperidade. Os primeiros dados da pesquisa apontaram para algumas características desta colônia, envolvendo questões jurídicas, lingüísticas, culturais, educacionais e gerontológicas. Fica evidente o processo de adaptação e o crescimento de identificação com o país que os acolheu. Apesar de todos os sucessos, o futuro da Colônia de Ivoti não é tranqüila. O sonho dos fundadores da Colônia em ter a sua própria terra não é necessariamente mais compartilhado por seus descendentes. Estudos adicionais serão necessários para aprofundar os aspectos apontados neste primeiro relatório. 